\title{
An Incentive Compatible Planning Procedure for Public Good Production: A Corrigendum
}

\author{
Jerry Green; Jean-Jacques Laffont \\ The Scandinavian Journal of Economics, Vol. 81, No. 3. (1979), pp. 443-444.
}

Stable URL:

http://links.jstor.org/sici?sici=0347-0520\%281979\%2981\%3A3\%3C443\%3AAICPPF\%3E2.0.CO\%3B2-O

The Scandinavian Journal of Economics is currently published by The Scandinavian Journal of Economics.

Your use of the JSTOR archive indicates your acceptance of JSTOR's Terms and Conditions of Use, available at http://www.jstor.org/about/terms.html. JSTOR's Terms and Conditions of Use provides, in part, that unless you have obtained prior permission, you may not download an entire issue of a journal or multiple copies of articles, and you may use content in the JSTOR archive only for your personal, non-commercial use.

Please contact the publisher regarding any further use of this work. Publisher contact information may be obtained at http://www.jstor.org/journals/sje.html.

Each copy of any part of a JSTOR transmission must contain the same copyright notice that appears on the screen or printed page of such transmission.

JSTOR is an independent not-for-profit organization dedicated to and preserving a digital archive of scholarly journals. For more information regarding JSTOR, please contact support@jstor.org. 


\section{AN INCENTIVE COMPATIBLE PLANNING PROCEDURE FOR PUBLIC GOOD PRODUCTION: A CORRIGENDUM}

\section{Jerry Green}

Harvard University, Cambridge, Massachusetts, USA

\section{Jean-Jacques Laffont}

Ecole Polytechnique, C.N.R.S., Paris, France

The problem mentioned by Mori arises from the fact that, for simplification, we did not maintain the exact parallelism between the mechanism presented and the static version of the incentive compatible mechanism referred to as the pivotal mechanism; see e.g. Green, Kohlberg \& Laffont (1976). By doing so we can insure the truthfulness of preference revelation at each $t$, and the results in Green \& Laffont (1978) are sustained.

With the same definition of the set of pivotal agents as in the paper, namely, $i \in P(t) \Leftrightarrow \sum_{j \neq i}\left(\psi^{j}(t)-\delta^{j} \gamma(x(t))\right)\left(\sum_{j} \psi^{j}(t)-\gamma(x(t))\right)<0$

and with one public good, the process must be defined as follows

$$
\begin{aligned}
& \dot{x}(t)=+1 \quad \text { if } \quad \sum_{i} \psi^{i}(t)-\gamma(t)>0 \\
& =0 \quad=0 \\
& =-1<0 \text {. }
\end{aligned}
$$

If $\sum_{i} \psi^{i}(t)-\gamma(t) \neq 0$

$$
\begin{aligned}
\dot{S}(t) & =-2 \sum_{i \in P(t)} \sum_{j \neq i}\left(\psi^{j}(t)-\delta^{j} \gamma(t)\right) \\
\dot{y}^{i}(t) & =-\delta^{i} \gamma(x(t)) \dot{x}(t)+2 \sum_{j \neq i}\left[\psi^{j}(t)-\delta^{j} \gamma(x(t))\right] \dot{x}(t)+\frac{1}{n} \dot{S}(t) \quad \text { if } i \in P(t) \\
& =-\delta^{i} \gamma(x(t)) \dot{x}(t)+\frac{1}{n} \dot{S}(t) \quad \text { if } i \notin P(t)
\end{aligned}
$$

If $\sum_{i} \psi^{i}(t)-\gamma(t)=0$

$$
\dot{y}^{i}(t)=-\left|\sum_{j \neq i}\left(\psi^{j}(t)-\delta^{j} \gamma(t)\right)\right|+\frac{1}{n} \sum_{i}\left|\sum_{j \neq i}\left(\psi^{j}(t)-\delta^{j} \gamma(t)\right)\right|
$$


It is also necessary to specify a rule for stopping the process. With one public good, as above, the natural rule is to stop at the instant that $\dot{x}(t)$ becomes zero. Convergence is assured, as demonstrated in the paper, as long as individuals behave myopically. Note that agents anticipate a non-zero transfer at this date, according to (1), but because (1) applies only at the very last instant of the process it affects individuals' utilities only infinitesimally. Nevertheless, transfers must be defined in this way, rather than being defined linearly in $\dot{x}(t)$ as we did in eqs. (5) and (6) in our original paper, if truth-telling is to be a dominant strategy.

The results of our paper for several public goods continue to be valid for the system given above. Under the rule: stop if and only if $\dot{x}_{k}(t)=0$ for all public goods $k$, convergence is assured when preferences are separable. Non-separable preferences with several public goods remain a problem. The counter-example in Section III.B of our paper can be modified straightforwardly to yield the same cyclical behavior under the system given above. For further details see, Green \& Laffont (1979, ch. 16).

The results of incentive compatibility obtained in our procedure are not as amazing as Mori believes and in no way contradict Hurwicz's theorem. Incentive compatibility is only local. That is, it reflects a first-order approximation to the change in utility at an instant in time. Hurwicz considers strategic behavior which would in principle allow manipulation of the entire path followed by the process. (His payoff function would presumably be $\lim _{t \rightarrow \infty} u_{i}(t)$ in our context.) This linearization of utility functions plus the individuals' neglect of their impact on the surplus generated, $\dot{S}(t)$, enables us to use the Clarke-Groves results in order to obtain incentive compatibility.

\section{References}

Green, J., Kohlberg, E. \& Laffont, J. J.: Partial equilibrium approach to the free rider problem. The Journal of Public Economics 6, 375-393, 1976.

Green, J. \& Laffont, J. J.: An incentive compatible planning procedure for public good production. The Scandinavian Journal of Economics 80, 20-33, 1978.

Green, J. \& Laffont, J. J.: Incentives in public decision making. North-Holland Press, Amsterdam, 1979. 